\title{
Korelasi antara Kelimpahan Kepiting dengan Kerapatan Mangrove di Desa Bedono Kecamatan Sayung Kabupaten Demak Jawa Tengah
}

\author{
Ardi Ristiyanto*, Ali Djunaedi, dan Chrisna Adhi Suryono \\ Departemen IImu Kelautan, Fakultas Perikanan dan IImu Kelautan, Universitas Diponegoro \\ Jl. Prof H.Soedharto S H, Tembalang, Semarang, Jawa Tengah 50275 Indonesia \\ ${ }^{*}$ Corresponding author, e-mail : ristiyantoardhy@gmail.com
}

\begin{abstract}
ABSTRAK : Hutan mangrove memiliki fungsi ekologis sebagai tempat pemijahan (spawning ground), asuhan (nursery ground), dan mencari makan (feeding ground). Tujuan dalam penelitian ini yaitu untuk mengetahui korelasi antara kelimpahan kepiting dengan kerapatan mangrove di ekosistem mangrove Desa Bedono, Kecamatan Sayung, Kabupaten Demak. Penelitian ini bersifat deskriptif eksploratif dengan pengambilan sampel menggunakan metode kualitatif dan penentuan lokasi sampling menggunakan purposive sampling method. Lokasi penelitian dibagi menjadi tiga stasiun yaitu A (Mangrove dekat muara), B (Tracking mangrove), C (Mangrove dekat Tambak). Sampel diambil dari plot sampling $5 \mathrm{~m}$ × $5 \mathrm{~m}$ dengan tiga kali pengulangan dan tiga waktu pengulangan di setiap stasiunnya. Hasil penelitian ini ditemukan 7 jenis kepiting yang termasuk ke dalam 4 famili, diantaranya adalah Ocypodidae (Uca vocans dan Uca coarctata), Grapsidae (Metoporgapsus latifrons dan Episesarma lafondi), Varunidae (Metaplax elegans dan Pseudograpsus albus) dan Sesarmidae (Parasesarma rutilimanum). Korelasi antara kelimpahan kepiting dengan kerapatan mangrove menunjukkan bahwa semakin tinggi nilai kerapatan mangrove maka semakin tinggi juga nilai kelimpahan kepiting. Nilai kelimpahan kepiting tertinggi terdapat di stasiun A (27633 ind/ha) dan kelimpahan terendah terdapat pada stasiun B (3833 ind/ha).
\end{abstract}

Kata Kunci : Ekosistem Mangrove; Komposisi Kepiting; Kelimpahan Kepiting; Brachyura.

\section{Correlation of an Abundance of Crabs with Mangrove Density in the Bedono Village Sayung District Demak Regency Central Java}

ABSTRACT : Mangrove forests have ecological functions as a spawning ground, nursery ground, and feeding ground. The purpose of this study is to determine the correlation of an abundance of crabs with the density of mangroves in the mangrove ecosystems of Bedono Village, Sayung District, Demak Regency. This research was descriptive explorative with sampling using qualitative methods and determining sampling locations using a purposive sampling method. The research location is divided into three stations, namely $A$ (Mangrove near the estuary), B (Tracking mangrove), $C$ (Mangrove near the Pond). Samples were taken from a sampling plot of $5 \mathrm{~m} \times 5 \mathrm{~m}$ with three repetitions and three repetitions of each station. The results of this study found 7 types of crabs belonging to 4 families, including Ocypodidae (Uca vocans and Uca coarctata), Grapsidae (Metoporgapsus latifrons and Episesarma lafondi), Varunidae (Metaplax elegans and Pseudograpsus albus) and Sesarmidae (Parasesarma rutilimanum). The correlation of the abundance of crabs with mangrove density shows that the higher the value of mangrove density, the higher the abundance of crabs. The highest value of crab abundance was found in station A (27633 ind/ha) and the lowest abundance was found at station B (3833 ind/ha).

Keywords: Mangrove Ecosystem; Crab Composition; Crab Abundance; Brachyura.

\section{PENDAHULUAN}

Desa Bedono memiliki masalah lingkungan yang serius, salah satunya yaitu rob yang menerpa desa ini dan menenggelamkan sebagian besar wilayah pemukiman penduduk pada tahun 1998. Wilayah Desa Bedono pada tahun 2015 memiliki luas sekitar 552 hektar, sementara luas sebelum tahun 1998 lebih dari 750 hektar. Penurunan luasan wilayah desa ini 
juga menyebabkan terjadinya perubahan pada ekosistem mangrove di Desa Bedono, hal ditambah lagi dengan adanya alih fungsi lahan mangrove menjadi tempat pariwisata dan budidaya tambak. Sehingga juga akan berdampak pada kehidupan ekologi yang berada di dalamnya (Pribadi dkk, 2012).

Ekosistem mangrove adalah tipe ekosistem yang khas terdapat di sepanjang pantai atau muara sungai yang dipengaruhi oleh pasang-surut air laut. Pada ekosistem mangrove terdapat kehidupan berbagai jenis organisme yang hidupnya bergantung pada mangrove (Afif dkk., 2014). Hutan mangrove memiliki beberapa fungsi diantaranya yaitu fungsi ekonomis, fungsi fisik, maupun fungsi ekologis. Fungsi ekologis hutan mangrove yaitu sebagai tempat pemijahan (spawning ground), asuhan (nursery ground), mencari makan (feeding ground) dan tempat bersarang berbagai spesies ikan, udang, kerang, burung dan biota lain (Pratiwi, 2009). Keberadaan kepiting di ekosistem mangrove dapat dijadikan sebagai indikator apakah hutan mangrove masih berfungsi dengan baik atau tidak. Menurut, Kalor dkk. (2018) kepiting merupakan spesies kunci di hutan mangrove yang berfungsi untuk mengkonversi nutrien dan mempertinggi mineralisasi, meningkatkan distribusi oksigen di dalam tanah, membantu siklus karbon, dan penyedia pakan alami bagi berbagai jenis biota di perairan.

Penelitian ini bertujuan untuk mengetahui hubungan kelimpahan kepiting (Brachyura) dengan kerapatan mangrove di ekosistem mangrove Desa Bedono, Kecamatan Sayung, Kabupaten Demak.

\section{MATERI DAN METODE}

Penelitian dilakukan pada bulan Februari 2019 di ekosistem mangrove, Desa Bedono, Kecamatan Sayung, Kabupaten Demak. Materi penelitian meliputi sampel kepiting yang di ambil di lokasi penelitian. Pengambilan sampel kepiting dilakukan dengan menggunakan plot sampling $5 \mathrm{~m} \times 5 \mathrm{~m}$. Cara pengambilan sampel dilakukan dengan hand picking pada saat kondisi air sedang surut supaya memudahkan untuk pengambilan sampel. Hal ini karena kepiting aktif bergerak pada saat kondisi air sedang surut (Sasekumar, 1974). Sampel yang ditemukan di akar mangrove dan di dalam lubang juga diambil dengan cara digali menggunakan sekop sedalam $10 \mathrm{~cm}$. Kepiting yang didapatkan diawetkan menggunakan alkohol 70\% (Wijaya dan Pratiwi, 2011). Identifikasi sampel kepiting dilakukan dengan menggunakan buku acuan antara lain dari (Sakai, 1976), FAO (1998), dan Hsi - Te Shih et al. (2016).

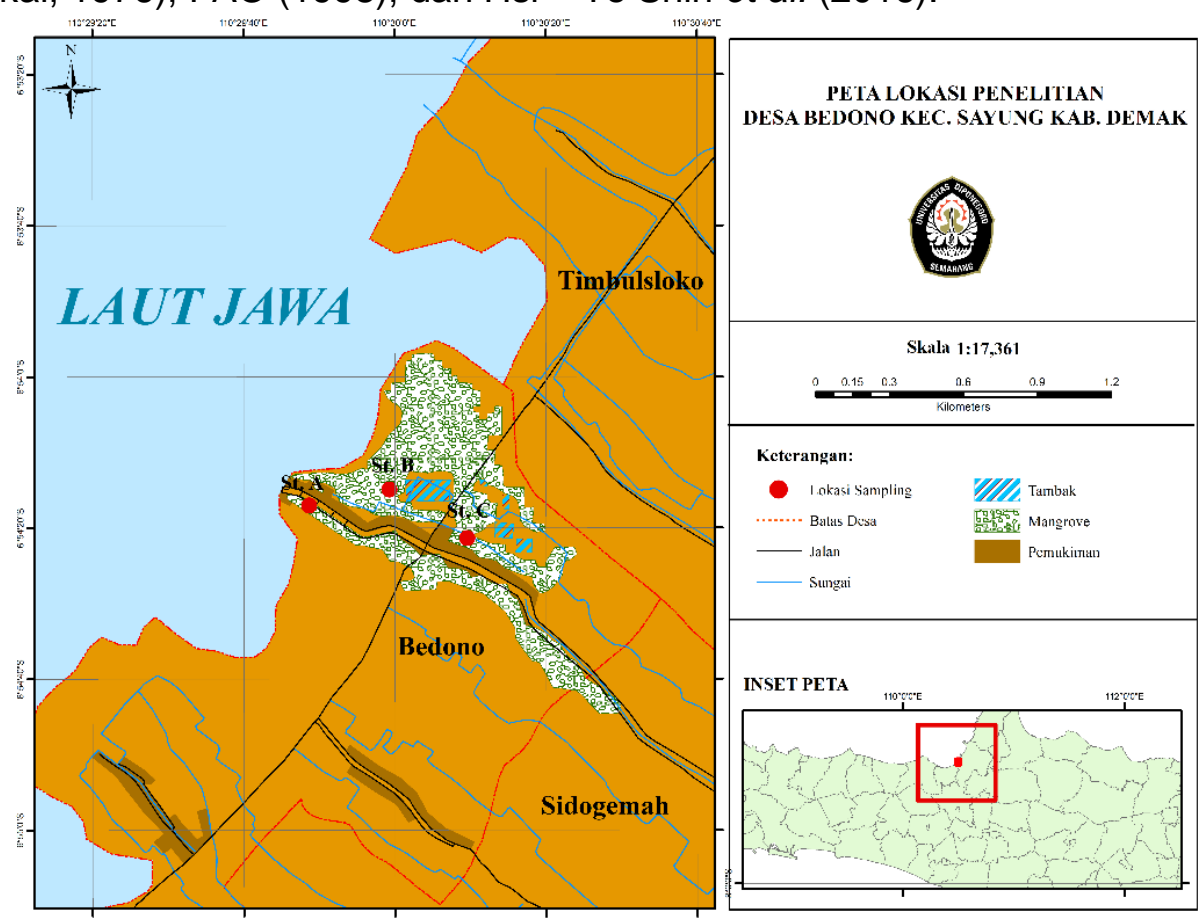

Gambar 1. Peta Lokasi Penelitian di Desa Bedono 


\section{Analisis Data}

Analisis data meliputi komposisi kepiting, kelimpahan kepiting dan korelasi antara kelimpahan kepiting dengan kerapatan mangrove. Kelimpahan suatu biota dalam suatu area ditentukan dalam jumlah individu/area (Odum, 1993), rumus kelimpahan (A) adalah:

$$
A=\frac{X_{\mathrm{i}}}{n_{\mathrm{i}}}
$$

Dimana : $\mathrm{A}=$ Kelimpahan $\left(\mathrm{ind} / \mathrm{m}^{2}\right) ; \mathrm{Xi}=$ Jumlah Individu dari jenis ke-i; $\mathrm{Ni}=$ Luasan Plot jenis ke-I ditemukan

\section{HASIL DAN PEMBAHASAN}

Komposisi kepiting (Brachyura) yang ditemukan di lokasi penelitian berjumlah 7 jenis yang terdiri dari 4 famili, yaitu Uca coarctata dan Uca vocans (Ocypodidae), Metopograpsus latifrons dan Episesarma lafondi (Grapsidae), Metaplax elegans dan Pseudograpsus albus (Varunidae), dan Parasesarma rutilimanum (Sesarmidae). Hasil penelitian menunjukkan bahwa Genus Parasesarma merupakan yang paling sering ditemukan di tiap stasiun dan setiap waktu pengambilan sampel.

Hasil yang didapatkan dalam penelitian ini, jenis Metopograpsus latifrons, Metaplax elegans dan Parasesarma rutilimanum merupakan jenis kepiting yang paling banyak ditemukan. Hal ini karena kepiting tersebut merupakan jenis kepiting yang paling umum ditemukan di ekosistem mangrove. Hasil ini sesuai dengan pernyataan Pratiwi dan Widyastuti (2013), kepiting yang biasa ditemukan di ekosistem mangrove berasal dari famili Grapsidae, Sesarmidae dan Ocypodidae. Rahayu dan Setyadi (2009) menambahkan bahwa tidak semua jenis kepiting dapat hidup di daerah mangrove, hanya jenis-jenis tertentu yang biasanya ditemukan seperti dari famili Ocypodidae, famili Sesarmidae, famili Grapsidae, famili Macropthalmidae, famili Porcellanidae, famili Portunidae dan famili Varunidae.

Menurut Hamidy (2010) menunjukkan bahwa Grabsidae di hutan mangrove mempunyai kemampuan adaptasi morfologi dan fisiologi terhadap suhu dan salinitas, yang menyebabkan adanya kemampuan untuk hidup pada seluruh habitat mangrove. Sesuai dengan pernyataan tersebut, jenis Metopograpsus latifrons dan Episesarma lafondi cukup banyak ditemukan di lokasi penelitian dan dan waktu pengulangan. Metopograpsus sp. sering ditemukan memanjat akar atau batang mangrove meskipun tidak terlalu tinggi, kepiting tersebut merupakan pemakan serasah dan daun mangrove.

Jenis kepiting Uca coarctata dan Uca vocans hanya ditemukan di stasiun A yang merupakan ekosistem mangrove dekat muara. Hal ini karena jenis kepiting tersebut pada umumnya ditemukan di pantai berlumpur dan di pinggiran hutan mangrove (Pratiwi, 2010). Spesies jenis Pseudograpsus albus juga hanya ditemukan di stasiun B pada minggu ketiga.

Tabel 1. Distribusi Kepiting yang Ditemukan di Lokasi Penelitian

\begin{tabular}{|c|c|c|c|c|c|c|c|c|c|c|}
\hline \multirow{2}{*}{ Famili } & \multirow{2}{*}{ Genus } & \multicolumn{3}{|c|}{ Stasiun A } & \multicolumn{3}{|c|}{ Stasiun B } & \multicolumn{3}{|c|}{ Stasiun C } \\
\hline & & 1 & 2 & 3 & 1 & 2 & 3 & 1 & 2 & 3 \\
\hline \multirow[t]{2}{*}{ Ocypodidae } & Uca coarctata & + & - & - & - & - & - & - & - & - \\
\hline & Uca vocans & + & - & - & - & - & - & - & - & - \\
\hline \multirow[t]{2}{*}{ Grabsidae } & Metopograpsus latifrons & + & + & - & - & - & + & + & + & + \\
\hline & Episesarma lafondi & - & - & + & + & - & + & + & + & + \\
\hline \multirow[t]{2}{*}{ Varunidae } & Metaplax elegans & + & + & + & + & + & + & + & + & + \\
\hline & Pseudograpsus albus & - & - & - & + & + & - & - & - & - \\
\hline \multirow[t]{3}{*}{ Sesarmidae } & Parasesarma rutilimanum & + & + & + & + & + & + & + & + & + \\
\hline & Jumlah Spesies Per Plot & 5 & 3 & 3 & 4 & 3 & 4 & 4 & 4 & 4 \\
\hline & Jumlah Spesies Total & & 6 & & & 5 & & & 4 & \\
\hline
\end{tabular}

Keterangan : + = ditemukan; - = tidak ditemukan 
Menurut Pratiwi dan Widyastuti (2013), peristiwa tersebut terjadi karena adanya pemilihan habitat yang mengakibatkan jenis tertentu dapat ditemukan di satu lokasi sedangkan jenis tersebut tidak ditemukan di lokasi lain.

$P$. rutilimanum merupakan salah satu jenis kepiting yang paling sering ditemukan di lokasi penelitian. Parasesarma rutilimanum merupakan spesies kepiting dari famili Sesarmidae. Menurut Bagus dan Aunurohim (2013), famili Grabsidae memiliki kemampuan mobilisasi yang tinggi karena dapat berpindah lokasi dengan mudah. Famili Grapsidae dan Sesarmidae merupakan jenis kepiting yang hidup pada batang dan akar pohon mangrove. Kepiting ini memanfaatkan daun mangrove sebagai makanannya dan memiliki peran penting sebagai detitrus dalam rantai makanan dan alur perpindahan energi dalam ekosistem mangrove.

Komposisi kepiting yang bervariasi antar stasiunnya kemungkinan disebabkan karena adanya pengaruh faktor lingkungan dan variasi habitat yang berbeda di setiap stasiun dan dan waktu pengulangannya. Hal ini juga dapat diketahui karena kepiting merupakan biota yang aktif bergerak sehingga dapat menyebabkan terjadinya perbedaan komposisi antar periode waktu pengambilannya. Menurut Pratiwi (2009), ekosistem mangrove merupakan daerah peralihan antara laut dan daratan sihingga memiliki perbedaan sifat lingkungan yang tajam sehingga menyebabkan kepiting harus beradaptasi dengan lingkungannya.

Korelasi antara kelimpahan kepiting dengan kerapatan mangrove di lokasi penelitian menunjukkan hasil yang positif yaitu bahwa semakin tinggi nilai kerapatan mangrove maka semakin tinggi juga nilai kelimpahan kepiting (Gambar 3). Kelimpahan kepiting paling tinggi terdapat di stasiun A di semua waktu pengulangan yang berkisar antara (27633 ind/ha). Kelimpahan tertinggi ini diduga karena pada stasiun A memiliki kerapatan mangrove yang paling tinggi (2733 ind/ha) dibandingkan dengan kedua stasiun lainnya, Stasiun C kerapatan mangrove (2367 ind/ha) dengan kelimpahan kepiting (22400 ind $/ \mathrm{m}^{2}$ )dan Stasiun B (1733 ind/ha) dengan kelimpahan kepiting (3833 ind/ha). Kerapatan ini menyebabkan tutupan kanopi mangrove menjadi cukup baik sehingga cocok untuk tempat hidup kepiting. Pradnya et al. (2011) menyatakan bahwa Crustacea sangat bergantung pada mangrove untuk bertahan hidup. Selain itu Crustacea hidup dengan membuat sarang berupa lubang pada subtrat. Aktivitas membuat lubang ini, dapat meningkatkan sirkulasi udara sedimen sehingga dapat mencegah pembentukan fitotoksin seperti $\mathrm{H}_{2} \mathrm{~S}$ sehingga terdapat hubungan antara tutupan kanopi mangrove dengan jumlah individu kepiting yang ditemukan di ekosistem mangrove.

Kepiting memiliki faktor lingkungan pembatas dalam mendukung kehidupannya, antara lain suhu, salinitas, $\mathrm{pH}$, tipe substrat dan bahan organik yang terkandung di dalam substrat. Perubahan kualitas ekosistem perairan dan substrat akan mempengaruhi kelimpahan dan keanekaragaman kepiting serta biota lainnya (Anggraeni dkk., 2015). Stasiun A dan C memiliki nilai kelimpahan yang cukup tinggi dan hampir sama di semua semua waktu pengulangan. Berbeda dengan stasiun B yang memiliki nilai kelimpahan yang cukup rendah. Hal ini karena di lokasi tersebut memiliki suhu yang mencapai $30,7^{\circ} \mathrm{C}$ yang melebihi batas toleransi bagi krustasea. Kisaran suhu optimal untuk krustasea menurut Wijaya dan Pratiwi (2011) adalah 28$30^{\circ} \mathrm{C}$. Tingginya suhu karena tutupan mangrove yang kurang karena stasiun B memiliki nilai kerapatan mangrove paling rendah yang menyebabkan intensitas sinar matahari banyak terpapar lansung mengenai substrat sehingga suhu meningkat.

Kondisi substrat juga berpengaruh terhadap kelimpahan kepiting. Stasiun A dan C memiliki substrat lanau atau lumpur yang cocok untuk tempat hidup kepiting, berbeda dengan stasiun B yang memiliki substrat lempung atau tanah liat yang kurang sesuai dengan tempat hidup kepiting. Keberadaan kepiting seperti misalnya genus Ocypode sangat dipengaruhi oleh beberapa faktor lingkungan seperti ukuran partikel pasir, kelembaban substrat, posisi zona pasang surut, derajat kemiringan zona pasang surut, ketersediaan makanan dan musim (Tureli et al., 2009).

Kepiting yang banyak ditemukan adalah dari jenis Metopograpsus latifrons, Metaplax elegans dan Parasesarma rutilimanum. Sesarmidae dan Varunidae memiliki kepadatan tertinggi kedua dan ketiga. Kalor dkk. (2018) menjelaskan bahwa Famili Sesarmidae cukup menonjol dalam perilaku, spesies ini sering disebut dengan kepiting pemanjat karena selalu memanjat akar dan batang pohon mangrove serta berdiam diri di sana. Hamidy (2010) menjelaskan bahwa Sesarmidae dapat hidup pada permukaan sedimen dan memiliki toleransi yang lebar 
terhadap salinitas air sehingga jenis ini dominan di ekosistem mangrove. Selama penelitian kepiting jenis Metopograpsus latifrons banyak ditemukan di akar dan batang mangrove serta dinding bangunan di lokasi penelitian. Kepiting ini dapat memanjat semua bagian pohon mangrove (akar, batang dan cabang) serta mencari makan dengan memakan daun mangrove, serasah mangrove maupun serangga kecil. Hamidy (2010) menunjukkan bahwa Grabsidae di hutan mangrove mempunyai kemampuan adaptasi morfologi dan fisiologi terhadap suhu dan salinitas, yang menyebabkan adanya kemampuan untuk hidup pada seluruh habitat mangrove.

Spesies Metaplax elegans memiliki nilai kelimpahan paling tinggi di lokasi penelitian, kemudian diikuti Parasesarma rutilimanum dan Metopograpsus latifrons. M. elegans ditemukan dalam jumlah melimpah karena spesies tersebut merupakan predator bagi kepiting intertidal lainnya. Menurut Handayani dkk. (2016) Kelompok Varunidae merupakan jenis krustasea yang memiliki rentang toleransi terhadap salinitas yang lebar dari air tawar hingga air laut.

Kepiting yang memiliki nilai kelimpahan yang rendah yaitu Uca coarctata, Uca vocans dan Pseudograpsus albus. Hal ini kemungkinan disebabkan karena kondisi lingkungan di lokasi penelitian yang sudah terganggu akibat adanya abrasi yang terus menerus sehingga menyebabkan kelimpahan kepiting jenis ini menjadi sedikit. Kepiting jenis Pseudograpsus albus hanya ditemukan di stasiun B. kepiting ini lebih menyukai substrat lumpur berpasir, sehingga kelimpahannya sangat sedikit. Kepiting tersebut merupakan kepiting pemakan serasah dan hewan-hewan laut yang telah mati. Secara umum keberadaan kepiting jenis Uca sp. dalam

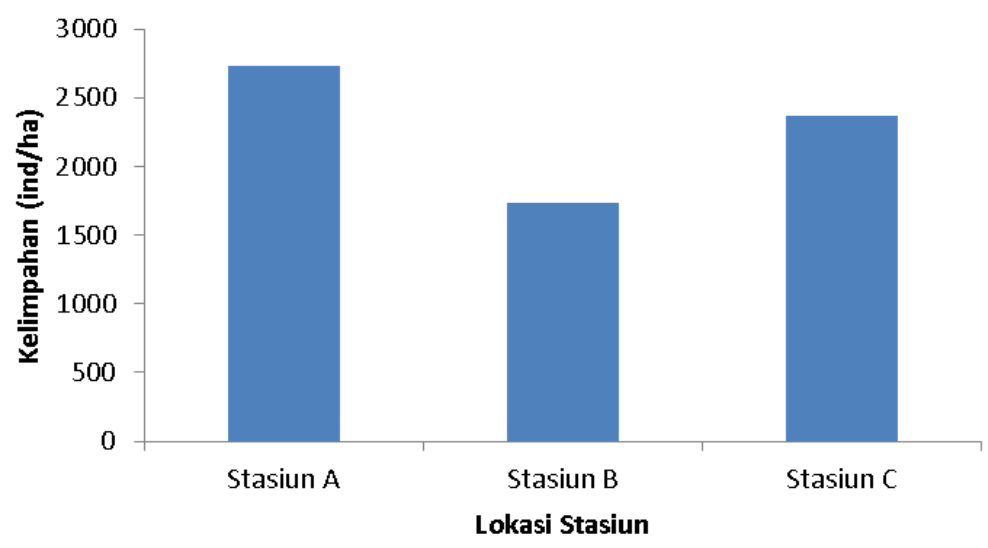

Gambar 2. Nilai Kelimpahan Kepiting (ind/ha) di Lokasi Penelitian.

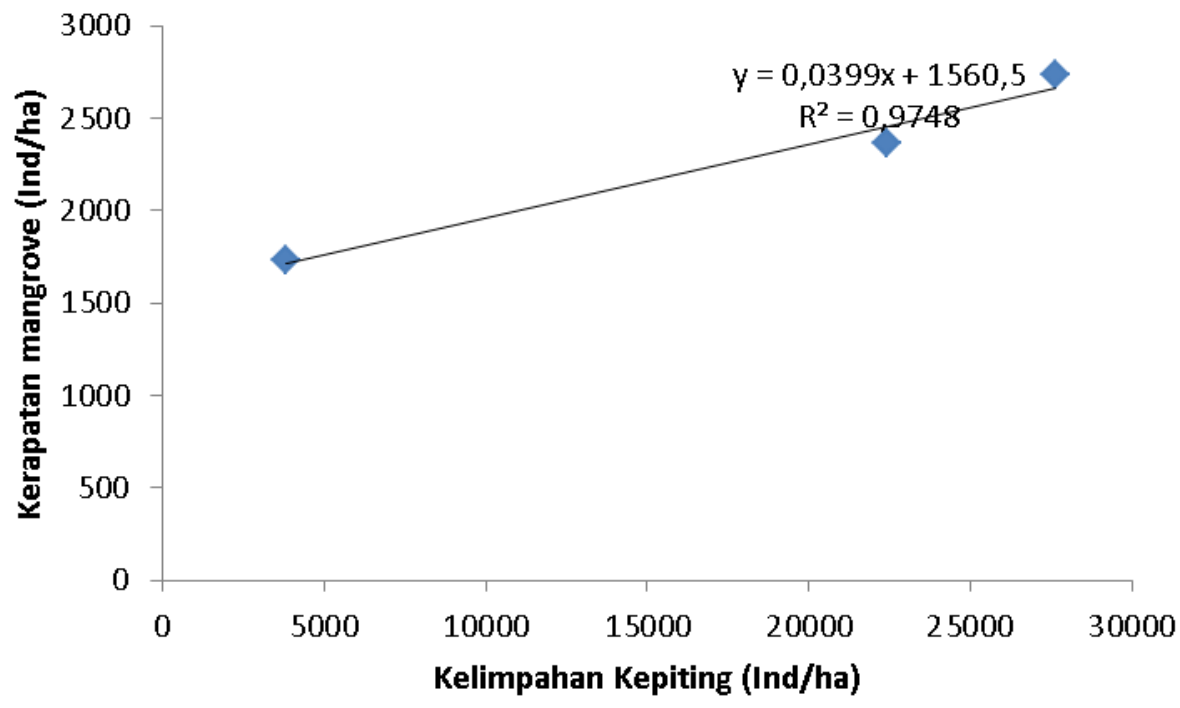

Gambar 3. Hasil Korelasi Kelimpahan Kepiting dengan Kerapatan Mangrove di Lokasi Penelitian. 
suatu ekosistem dapat dijadikan sebagai indikator kondisi lingkungan karena kepiting ini memiliki hubungan timbal balik yang saling menguntungkan bagi lingkungannya. Kepiting ini memiliki cara makan deposit feeder (pemakan deposit) ysng memakan deposit di permukaan substrat. Kepiting tersebut merupakan kepiting pemakan serasah dan hewan-hewan laut yang telah mati (Pratiwi, 2010).

Biota yang hidup termasuk kepiting keberadaannya sangat dipengaruhi oleh parameter lingkungan pembatas, adanya ketersediaan makanan dan kompetisi antar jenis juga dapat menjadi faktor biotik dari kelimpahan biota di mangrove.Kondisi bahan organik di lokasi penelitian juga menunjukkan bahwa di stasiun $A$ dan stasiun $C$ memiliki kriteria sedang, di stasiun B memiliki kriteria yang rendah sehingga juga berpengaruh terhadap kelimpahan kepiting di masing-masing stasiunnya. Dari hasil yang didapatkan dapat diketahui bahwa kondisi lingkungan dan kehidupan memiliki hubungan yang saling mempengaruhi.

\section{KESIMPULAN}

Korelasi antara kelimpahan kepiting dengan kerapatan mangrove menunjukkan hasil yang positif yaitu bahwa semakin tinggi nilai kerapatan mangrove maka semakin tinggi juga nilai kelimpahan kepiting yang didapatkan. Kelimpahan kepiting tertinggi terdapat di stasiun A (27633 ind/ha) dengan kerapatan mangrove terbesar (2733 ind/ha) dan kelimpahan terendah terdapat pada stasiun B (3833 ind/ha) dengan kerapatan mangrove terendah (1733 ind/ha).

\section{UCAPAN TERIMA KASIH}

Artikel ini merupakan bagian dari skripsi yang berjudul "Komposisi dan Kelimpahan Kepiting (Brachyura) di Ekosistem Mangrove Desa Bedono Kecamatan Sayung Kabupaten Demak". Penulis mengucapan terima kasih kepada seluruh pihak yang telah membantu selama penelitian. Kepada reviewer jurnal marine research disampaikan penghargaan atas review yang sangat berharga pada artikel ini.

\section{DAFTAR PUSTAKA}

Afif, J., Ngabekti, S., \& Pribadi, T.A. 2014. Keanekaragaman makrozoobentos sebagai indikator kualitas perairan di ekosistem mangrove Wilayah Tapak Kelurahan Tugurejo Kota Semarang. Journal Life Science, 3(1): 47-52

Anggraeni, P., Dewi, E. \& Rianta, P. 2015. Sebaran kepiting (Brachyura) di Pulau Tikus, Gugusan Pulau Pari, Kepulauan Seribu. Prosiding Seminar Nasional Masyarakat Diversitas Indonesia, April 2015., 1(2):213-221.

Bagus, K.S. \& Anunurohim. 2013. Studi distribusi makrofauna benthos di zonasi mangrove Pulau Poteran, Madura, Jawa Timur. Journal Sains dan Seni Pomits, 2(1): 1-5.

FAO. 1998. World Reference Base for Soil Resources, by ISSS-ISRIC-FAO. World Soil Resources Report No. 84. Rome., p. 1046-1055.

Hamidy, R. 2010. Structure and diversity of crabs community in mangrove area, marine station of Riau University, Purnama Dumai. Journal Environment Science., 2(4): 81-91.

Handayani, O.T., Sri, N. \& Nana, K.T.M. 2016. Keanekaragaman Crustacea di Ekosistem Mangrove Wilayah Tapak Kelurahan Tugurejo Kota Semarang. Journal Life Science, 5(2): 100-107.

Hsi-Te, S., Peter, K.L.N., Peter, J.F.D., Christoph, D.S., Michael, T., Reza, N., Diana, J. \& MinYun, L. 2016. Systematics of the Family Ocypodidae Rafinesque, 1815 (Crustacea: Barchyura), Based on Phylogenetic Relationships, with a Reorganization of Subfamily Rangkings and a Review of the Taxonomic Status of Uca Leach, 1814, Sensu Lato and its Subgenera. Journal Raffles Bulletin of Zoology, 64:139-175.

Kalor, J.D., Dimara, L., Ottouw, G. \& Piaki, K., 2018. Status kesehatan dan uji spesies indikator biologi ekosistem mangrove Teluk Yotefa Jayapura. Journal Biosfera, 35(1): 1-9.

Kochl, V. \& Wolff, M. 2002. Energy Budget and Ecological Role of Mangrove Epibenthos in the Caete Estuary, North Brazil. Marine Ecology Progress Series, 228(1):119-130. 
Odum, E.P. 1993. Dasar-Dasar Ekologi. Terjemahan Tjahjono Samingan. Gadjah Mada University Press. Yogyakarta. $694 \mathrm{hlm}$.

Pradnya, D.B., Kusuma, N. \& Kakati, V.S. 2011. Biodiversity of Crabs in Karwar Mangrove Environment West Coast of India. Rec Research Sci Tech., 3(4): 1-5.

Pratiwi, R. 2009. Komposisi Keberadaan Krustasea di Mangrove Delta Mahakam Kalimantan Timur., Journal Makara Sains, 13(1):65-76.

Pratiwi R. 2010. Asosiasi Krustasea di ekosistem padang lamun perairan Teluk Lampung. Jurnal IImu Kelautan, 15 (2):66-76.

Pratiwi, R., \& Widyastuti, E. 2013. Pola Sebaran dan Zonasi Krustasea di Hutan Bakau Perairan Teluk Lampung. Journal Zoo Indonesia., 22(1):11-21.

Pribadi, R., Abdul, R.Z. \& Suryono, C.A. 2012. Kajian Kondisi Lahan Mangrove di Desa Bedono, Kecamatan Sayung, Kabupaten Demak dan Kelurahan Mangunharjo, Kecamatan Tugu, Kota Semarang. Journal of Marine Research., 1(2):88-97.

Rahayu, D.L., \& Setyadi, D. 2009. Mangrove Estuary Crabs of The Mimika Region, Papua, Indonesia. PT Freeport Indonesia-LIPI. Papua, $154 \mathrm{hlm}$.

Sakai, T. 1976. Crabs of Japan and The Adjacent Seas Plates. Kodarian LTD. Japan, Vol. 1, $773 \mathrm{p}$.

Sasekumar, A. 1974. Distribution of Macrofauna on Malaya Mangrove Shore. The Journal of Animal Ecology (43): $51-69$.

Tureli, C., Duysak, O., Akamca, E., \& Kiyagi, V. 2009. Spatial Distribution and Activity Pattern of The Ghost Crab, Ocypode Cursor (Linnaeus, 1758) in Yumurtalik Bay,North-Eastern Mediterranian-Turkey. Journal of Animal \& Veterinary Advances., 8(1) 165-171.

Wijaya N.I. \& Pratiwi, R. 2011. Distribusi spasial Krustasea di perairan Kepulauan Matasiri, Kalimantan Selatan. Jurnal IImu Kelautan., 16(3):125-134. 